\title{
Two Uveal Melanomas in One Eye: A Choroidal Nevus Giving Rise to a Melanoma in an Eye with a Separate Large Choroidal Melanoma
}

\author{
Alisa J. Prager Larissa A. Habib Klaus J. Busam Brian P. Marr \\ Memorial Sloan Kettering Cancer Center, New York, NY, USA
}

\section{Established Facts}

- Multifocal uveal melanomas are rare and can be associated with BRCA-associated protein 1 mutations, familial cancer syndromes, and ocular melanocytosis.

\section{Novel Insights}

- Multifocal melanomas can be found in patients without known predisposing risk factors such as ocular melanocytosis or known germline genetic mutations.

- Choroidal melanomas may arise from benign nevi and may occur focally within a larger benign lesion, emphasizing the importance of close follow-up.

\section{Keywords}

Multiple melanoma · Multifocal melanoma · Uveal melanoma · Choroidal melanoma · Histopathology · Choroidal nevus

\footnotetext{
Abstract

Multifocal uveal melanomas are extremely rare. In this case report, we describe a patient with 2 independent uveal melanomas in the same eye. A 52-year-old woman presented with a large choroidal melanoma and a smaller ciliary body mass, clinically thought to be a nevus, in her left eye. Enucleated specimen showed 2 primary lesions that were anatom-
}

ically separate. Lesion 1 was a melanoma and lesion 2 was a melanoma arising centrally from a nevus. Both lesions harbored GNAQ mutations. This patient had no family history of uveal melanomas or signs of ocular melanocytosis and was negative for the BAP1 mutation. This case demonstrates how multifocal uveal melanomas can arise in patients who lack genetic predisposition for the disease. Furthermore, this case is one of the few that have shown, histopathologically, a small focus of malignant cells developing from a benign population within a nevus, which highlights the importance of closely monitoring nevi for signs of malignancy.

(c) 2018 S. Karger AG, Base

\section{KARGER}

(c) 2018 S. Karger AG, Basel

E-Mail karger@karger.com

www.karger.com/oop
Brian P. Marr, MD

Columbia University, Department of Ophthalmology

635 West 165 th Street

New York, NY 10032 (USA)

E-Mail Bpm2133@cumc.columbia.edu 


\section{Introduction}

Multifocal uveal melanomas are extremely rare [1-5]. Evidence suggests that uveal melanoma can either arise de novo [6] or from preexisting nevi [7]. The purpose of this report is to describe a patient with two independent uveal melanomas in the same eye, with one arising from a nevus.

\section{Case Report}

A 52-year-old woman with no prior ocular or medical history presented with complaints of decreased peripheral vision in her left eye. Family history was negative for cancer and the right eye was unremarkable. Best-corrected visual acuity was 20/20 OD and 20/150 OS and intraocular pressure was $14 \mathrm{~mm} \mathrm{Hg} \mathrm{OD} \mathrm{and} 16 \mathrm{~mm}$ $\mathrm{Hg}$ OS. There were no signs of episcleral melanocytosis. Fundoscopic exam revealed no choroidal melanocytosis, confirmed with transillumination. A large pigmented mushroom-shaped choroidal melanoma was seen (lesion 1) overhanging the optic nerve nasally and occupying most of the nasal hemisphere (Fig. 1). This lesion measured $10.6 \mathrm{~mm}$ in diameter and $11.2 \mathrm{~mm}$ in thickness. $\mathrm{B}$-scan ultrasonography using the $10-\mathrm{MHz}$ transducer showed cystic cavities, surrounding subretinal fluid, intravascular pulsations, and no extrascleral extension (Fig. 2). Further ocular examination revealed a $9 \times 1.7 \mathrm{~mm}$ ciliary choroidal mass superiorly, which was clinically thought to represent a nevus (lesion 2). Ultrasonic biomicroscopy of lesion 2 showed a 1.7 -mm lesion extending from the ciliary body and pars plana into the choroid with medium reflectivity and no subretinal fluid, intrinsic vascular pulsations, or extraocular extension. The AJCC classification of tumor 1 was T3a and tumor 2 was T1b.

The patient underwent enucleation (Fig. 2) and the specimen was sent for histopathological and immunohistochemical analysis. The enucleated specimen confirmed 2 primary lesions by serial sections in the equatorial plane (Fig. 3). We were unable to visualize the base of the larger lesion due to fresh tissue harvesting at the time of the enucleation. Lesion 1 was a uveal melanoma, predominantly mixed cell type with rupture of Bruch's membrane and
Fig. 1. a Wide-angle fundoscopic image showing the large choroidal melanoma in the posterior pole and the smaller lesion superiorly. b Transillumination of enucleated specimen revealed two distinct lesions.
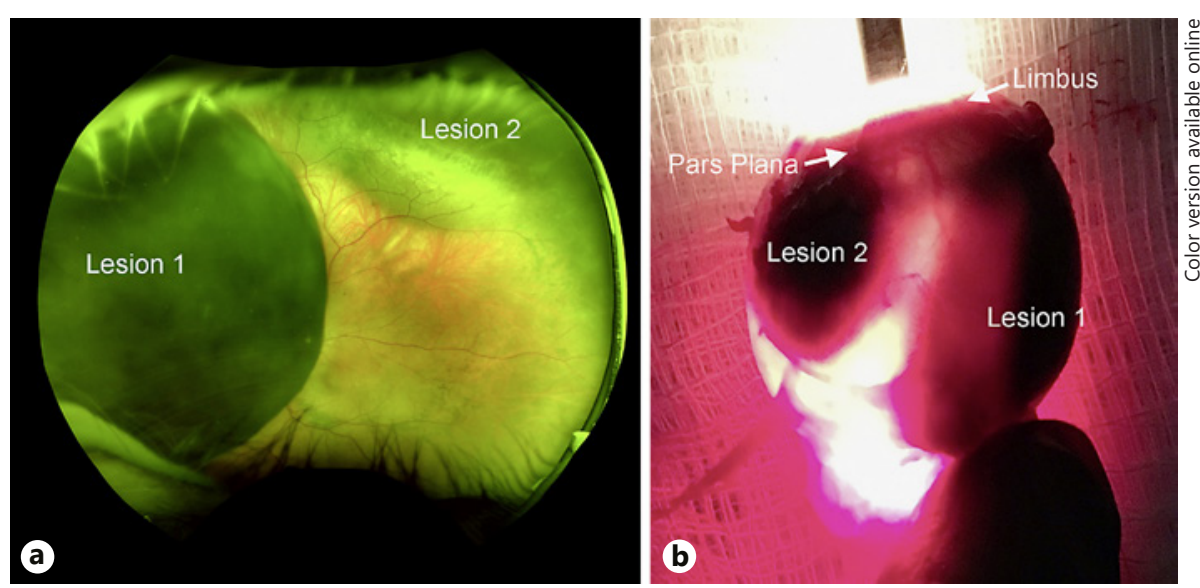
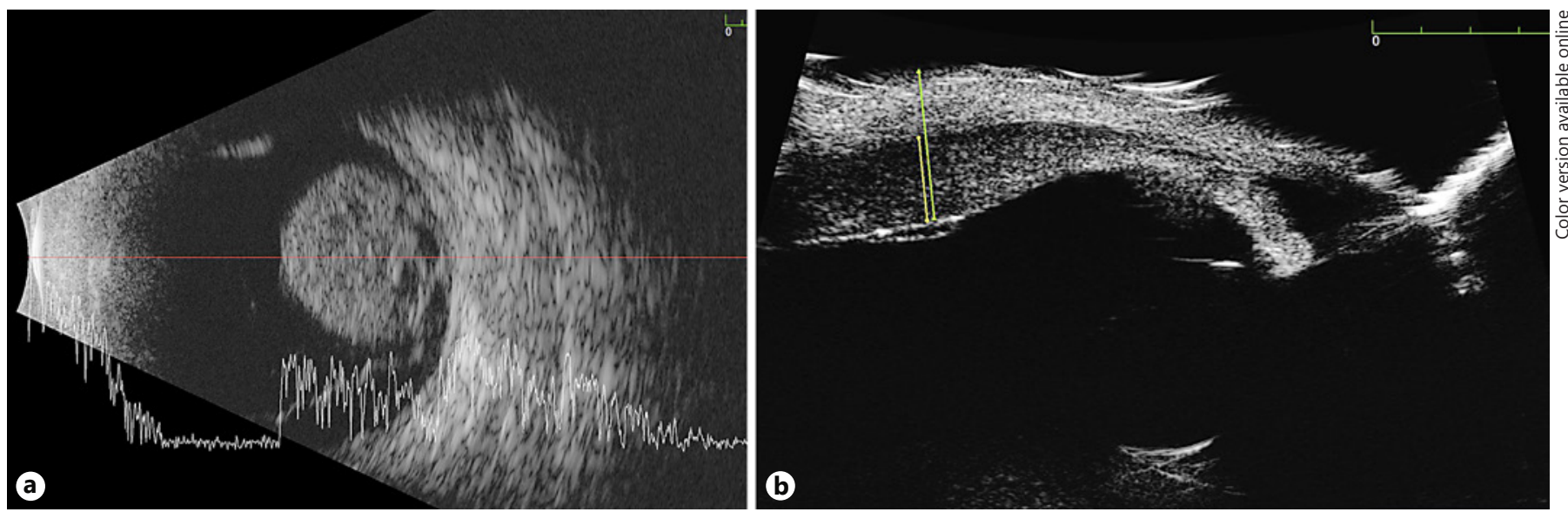

Fig. 2. B-scan of larger posterior lesion (a) and ultrasonic biomicroscopy of ciliary body lesion (b). 
formation of cavitations within the herniated component. Lesion 2 was a choroidal nevus with a focus of melanoma, predominantly spindle cell type with pronounced vasculogenic mimicry, arising within the lateral portion of the lesion. Both tumors expressed $G$ protein alpha-subunit (GNAQ) c.626A>T (Q209L) mutations. BAP1 mutation was negative. Gene expression profiling using Castle Biosciences classified the main tumor (lesion 1) as type IA. The patient has been followed for 16 months and is currently alive with no evidence of metastatic disease on imaging.

\section{Discussion}

Multifocal uveal melanomas have been associated with BRCA-associated protein 1 (BAP 1) mutations [8], familial cancer syndromes [9], and ocular melanocytosis [10$12]$. While there have been over 20 reports of multiple melanomas in the same eye $[1,2,4,5,13]$, this case is unique given the identification of 2 distinct melanomas

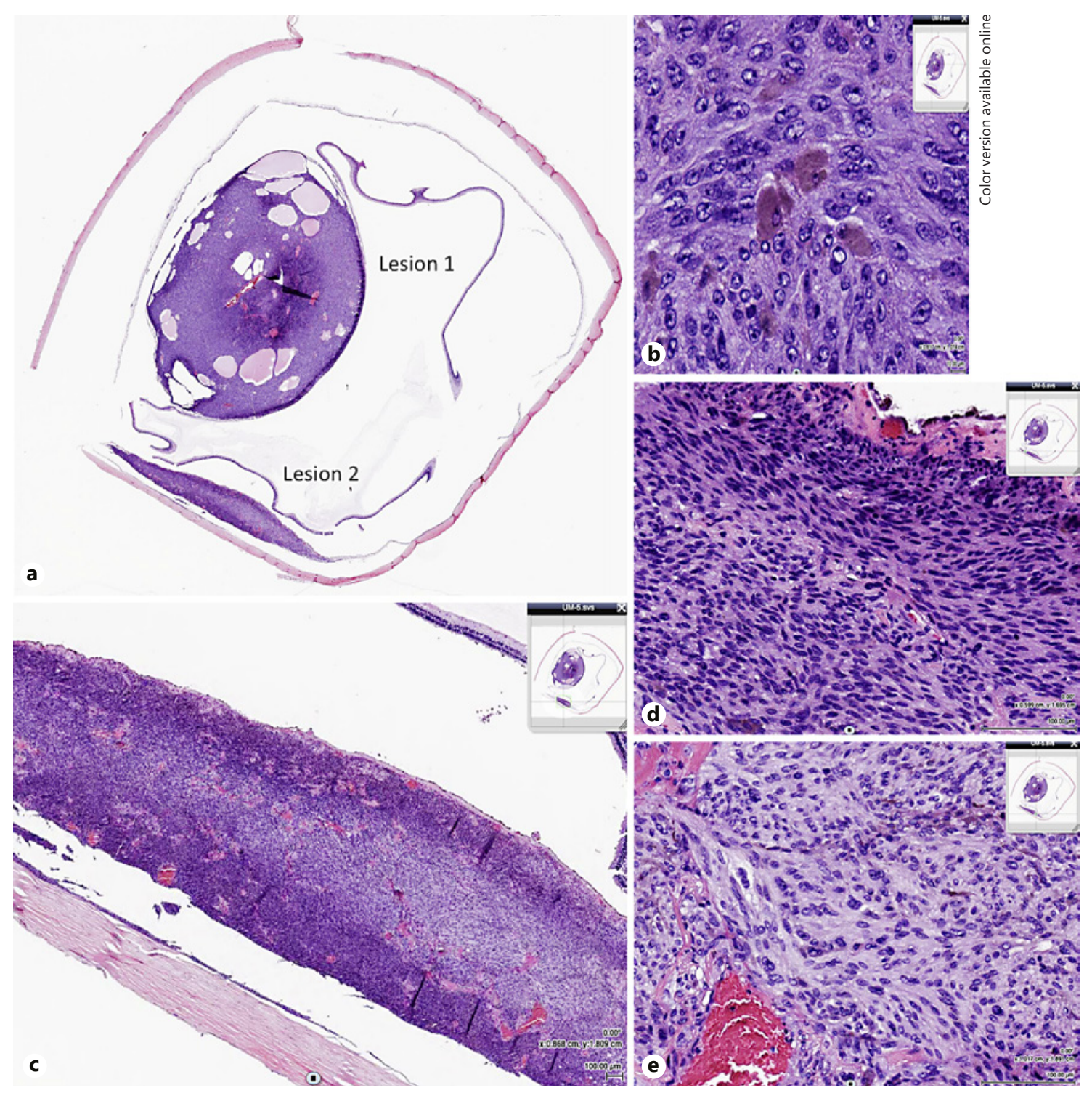

Fig. 3. a Enucleation specimen showing 2 distinct uveal melanomas stained with hematoxylin-eosin. For $\mathbf{b}-\mathbf{e}$, the upper right corner references location of high magnification image in main specimen. $\mathbf{b}$ Higher magnification of lesion 1 showing melanoma cells with large irregular nuclei $(40 \times)$. c Lesion 2 with foci of melanoma arising from a background of nonmalignant melanocytes $(3 \times)$. d, e Higher magnification of lesion 2 with area of nevus showing benign appearing nevus cell $(\mathbf{d}, 13 \times)$ and area showing melanoma cells with large irregular nuclei $(\mathbf{e}, 20 \times)$. 
with 1 arising from a nevus in the absence of clinical melanocytosis. The smaller lesion was thought to clinically represent a nevus; however, histopathologic analysis revealed a central component of melanoma cells.

GNAQ mutations are commonly seen in both nevi and melanomas [14]. This mutation is hypothesized to occur early in tumorigenesis and activate the RAF/MEK/ ERK pathway [15]. On the other hand, BAP1, SF3B1, or EIF1AX mutations are thought to trigger downstream molecular events during tumor progression and some are associated with poorer prognosis than others [16]. We found GNAQ mutations in both lesions, this raises suspicion that there may have been a field of genetically predisposed cells that gave rise to these 2 lesions as seen in ocular melanocytosis despite the fact that there was no clinical evidence. Furthermore, the tumors did not harbor the BAP1 mutation, making a germline predisposition less likely. And she remains without further evidence of disease.

This case demonstrates that multiple choroidal melanomas can arise in one eye even in patients without ocular melanocytosis or genetic predisposition. Further- more, lesions that clinically appear as nevi may harbor small nests of malignant cells, highlighting the importance of close follow-up. Further cytogenetic studies of these types of tumors may help us gain a better understanding of the pathogenesis of choroidal nevi and melanomas.

\section{Acknowledgement}

We thank Dr. Folberg for assistance with the histopathology slides and the manuscript.

\section{Statement of Ethics}

This report does not contain any personal information that could lead to the identification of the patient.

\section{Disclosure Statement}

The authors have no financial interests, conflicts of interest, or disclosures related to this study.

\section{References}

1 Nissen EJ, Kalirai H, Damato B, Heimann H, Coupland SE: Two distinct uveal melanomas in the same eye. JAMA Ophthalmol 2015;133: 1094-1096.

-2 Dithmar S, Volcker HE, Grossniklaus HE: Multifocal intraocular malignant melanoma: report of two cases and review of the literature. Ophthalmology 1999;106:1345-1348.

3 Volcker HE, Naumann GO: Multicentric primary malignant melanomas of the choroid: two separate malignant melanomas of the choroid and two uveal naevi in one eye. $\mathrm{Br} \mathrm{J}$ Ophthalmol 1978;62:408-413.

-4 Hadden PW, Damato BE: Consecutive choroidal melanoma in the same eye of a patient. Am J Ophthalmol 2003;135:728-729.

5 Blumenthal EZ, Pe'er J: Multifocal choroidal malignant melanoma: at least 3 melanomas in one eye. Arch Ophthalmol 1999;117:255-258.

-6 Sahel JA, Pesavento R, Frederick AR Jr, Albert DM: Melanoma arising de novo over a 16-month period. Arch Ophthalmol 1988; 106:381-385.
You QS, Xu L, Jonas JB, Wang S, Yang H: Change in choroidal nevi during a 5-year follow-up study: the Beijing Eye Study. Br J Ophthalmol 2010;94:575-578.

-8 Rao R, Pointdujour-Lim R, Ganguly A, Shields CL: Multifocal choroidal melanoma in a patient with germ line BRCA-associated protein 1 mutation. Retin Cases Brief Rep 2018;12:1-4.

-9 Singh AD, Shields CL, Shields JA, Eagle RC, De Potter P: Uveal melanoma and familial atypical mole and melanoma (FAM-M) syndrome. Ophthalmic Genet 1995;16:53-61.

10 Pomeranz GA, Bunt AH, Kalina RE: Multifocal choroidal melanoma in ocular melanocytosis. Arch Ophthalmol 1981;99:857-863.

11 Honavar SG, Shields CL, Singh AD, Demirci $\mathrm{H}$, Rutledge BK, Shields JA, Eagle RC Jr: Two discrete choroidal melanomas in an eye with ocular melanocytosis. Surv Ophthalmol 2002; 47:36-41.
2 Shields CL, Eagle RC, Ip MS, Marr BP, Shields JA: Two discrete uveal melanomas in a child with ocular melanocytosis. Retina 2006;26: 684-687.

13 Tappin MJ, Parsons MA, Sisley K, Rees RC, Rennie IG: Two cases of double melanoma of the uvea. Eye (Lond) 1996;10:600-602.

14 Van Raamsdonk CD, Bezrookove V, Green G, Bauer J, Gaugler L, O’Brien JM, Simpson EM, Barsh GS, Bastian BC: Frequent somatic mutations of GNAQ in uveal melanoma and blue naevi. Nature 2009;457:599-602.

15 Onken MD, Worley LA, Long MD, Duan S, Council ML, Bowcock AM, Harbour JW: Oncogenic mutations in GNAQ occur early in uveal melanoma. Invest Ophthalmol Vis Sci 2008;49:5230-5234.

16 Decatur CL, Ong E, Garg N, Anbunathan H, Bowcock AM, Field MG, Harbour JW: Driver mutations in uveal melanoma: associations with gene expression profile and patient outcomes. JAMA Ophthalmol 2016;134:728733. 